\title{
The "First" Horse
}

\author{
Barbara Ghiringhelli \\ Department of Classical Studies, Humanities and Geography, Faculty of Arts, Tourism and Markets, IULM University, Italy
}

Copyright $(2016$ by authors, all rights reserved. Authors agree that this article remains permanently open access under the terms of the Creative Commons Attribution License 4.0 International License

\begin{abstract}
From an anthropological perspective, this research aims to shed light on the relationship between the human and the horse, but specifically on the relationship between an owner (first time horse owner) and his/her horse. It will also delve into how that relationship is affected by cultural aspects with respect to origin as well as the level of competency held by the owner/rider. What specific intercourses can exist to create a better bond between human and horse? What the ideas of our informants about horses' individuality and horses' mental capacities? And about what kind of relationships that are possible between human and horse? My research is conceived as an ethnographic study presenting an analysis of narrative data collected in twenty-five open-ended interviews with horse people (all owners/riders) who participate in different equestrian sports in two specific provinces of Italy - Umbria and Lombardia. What has emerged is the underestimation of the importance of the physical and mental characteristics of the horse at the beginning of the relationship. Elements that emerge as important factors can influence the positivity or negativity of the relationship. A greater consciousness of the subjectivity of the horse is needed in horse-buying process to better interact and develop a positive relationship with horses. Over time, owners/riders acquired a sense that horses are partners, subjects with minds and agency of their own.
\end{abstract}

Keywords Anthropology, Horse-human Relationships, Multispecies Ethnography, Mutual Becoming, Intersubjectivity

\section{Introduction}

Animals have historically played a large role in anthropological studies, albeit in a secondary fashion. Animals have long served as objects of study but were rarely considered to be "subjects of a life" [1]

Until very recently, academia has largely ignored the human-animal interactions. This invisibility - in scholarly inquiry - was perhaps as great as the presence of animals in our daily lives. We share the world with a lot of other animal, and many of us come into contact with some of these animals on a daily basis. Animals exist in our homes as pets, on farms and on industrial farms, fur farms, in scientific laboratories, at work, as companions and aids to the disabled and therapy animals in schools, hospitals, or even prison. Animals exist in zoo, marine mammal parks, and other venues in which they perform for human entertainment. Animals increasingly exist in virtual worlds, animal exist in the wild although those arenas are becoming fewer. Animal exist out of place and in the myths, legends, and folktales of people around the world. The religion of all societies incorporates animals into their cosmologies, beliefs, practices, and symbolism. [2, 3]

The study of human-animal interactions, and the resulting human-animal relationships and bonds which are set up as a consequence, is currently a topical issue in socio-cultural anthropology. The interest in human-animal interactions in contemporary anthropology can be regarded as a consequence of the so-called reflexive turn. Researcher over the last ten years suggests a re-examination of our relationship with other species often referred to as the species turn. [4-6]Recent studies of the relationships between humans and other animals have contributed to a revolutionary change in our perspectives about anthropos' place in the world. These studies invite us to explore different ways of knowing and being in the world, ways that are determinedly less anthropocentric and humanist; ways that acknowledge and celebrate co-presence. [7]

As Shanklin [8] noted in her own review of anthropological interest in animals up until the mid-1980s "the investigation of human and animal interaction may well be one of the most fruitful endeavors of anthropology". Creatures previously appearing on the margins of anthropology have been pressed into the foreground in recent ethnography. Animals were actually quite central to understanding anthropology and its history - and important for anyone interested in understanding humans. We can learn about human worlds when we pay attention to the mutually co-constituting relationships between people and other animals.

In 1989 anthropologist Barbara Noske [9] issued a clarion call urging anthropologists to acknowledge and challenge the anthropocentricity of the anthropological endeavour. Writing extensively about the relationship with human and other animals, Haraway [10] contends that we are 
companion species, participants in on-going processes of "becoming-with" each other in natural cultural practices. Donna Haraway tells us that "If we appreciate the foolishness of human exceptionalism then we know that becoming is always becoming with, in a contact zone where the outcome, where who is in the world, is at stake". In 2007, Kohn [11] taking up the gauntlet laid down by Noske and proposes anthropology of life, "an anthropology that is not just confined to the human but is concerned with the effects of our entanglements with other kinds of living selves". In this context the animal turn "has encouraged a more balanced consideration of the multifarious and often unacknowledged roles that animals play in human societies. Lastly, the post-humanist recognition that other animals are indeed integral actors within human social lives and are therefore worthy of anthropological attention in their own right has led to a move to bring in the animal; to consider human-animal interactions from the perspective of the nonhuman as well as the human." [12]. So, post-humanism has enabled us to see that humans are just one species among many whose lives are inextricably linked and mutually dependent [13]. Multispecies ethnography is particularly attentive to Becoming's, what Eben Kirksey and Stefan Helmreich [14] describe as new kinds of relations emerging from nonhierarchical alliances, symbiotic attachments, and the mingling of creative agents. Humans and animals instead become with each other, in interspecies communications that ontologically inform the personalities and identities of both. Multispecies ethnographers are studying contact zones where lines separating nature from culture have broken down. [15-16]

Such other-than-human creatures tend to be considered within the ecosystems where they play specific roles or have carved out particular niches. We live in a multispecies world that is described from Abram David. [17] As a "more than human world". In Waldau's [18] words, "Our citizenship in such a multispecies world not only suggests the possibility of non-anthropocentric worldviews - our awareness of this larger community also begs a broader, more inclusive perspective than the human-centered and exceptionalist approaches that dominate our education establishment, political realms, legal systems, businesses and many religious institutions. What further begs such breadth and inclusion is the fact that personally, ecologically and thus ethically each of us lives in a fascinating and distinctive series of nested communities replete with other-than-human neighbors."

\section{Human-Horse Relationships}

Human-horse relationships have a long history. The horse holds a unique place among domesticated animals. Whether as food source or beasts of burden, as objects of worship, sacrifice or study; as tools in science, therapy or agriculture; or as travelling, sporting or battle workers, horses have influenced human societies since the two species came together.

Contrarily to many other domestic ungulates, which are mostly kept for breeding, meat production, milk production or wool production, horses "rapidly" acquired a mixed status: source of food for some, for leisure and sport for others, or, less frequently, a working companion in rural areas. [19]

Relationships between horses and humans are complex and multi-faceted, incorporating a wide variety of practices and purposes. Horses are very social animals. Horses are capable of emotions and feelings. Horses are active and reactive agents in the formation of social relationships with humans. According to Haraway [20], the encounters can be understood as forms of "becoming with" animals, as material-semiotic and intersubjective processes of mutual being and doing, interaction and transformation. The daily human horse interactions are very varied and include both positive and negative events, leading to a more or less balanced relationship. Domesticated horses have an advanced ability to assess a human's emotional well-being, having been side by side with humans for centuries. Horses "know" humans and will attempt to trust and partner with humans, to form relationships.

The equine community is nowadays diversified to the extent that we are able to identify different norms and ideas about such things as horses' individuality or horses' mental capacities, and also about what kind of relationships that are possible between human and horse. Interactions and relationships do not occur accidentally, or incidentally.

In all cases, humans and nonhumans are engaged in a relationship, and even though many of those relationships are not reciprocal, and many are coerced, these relationships do form the basis for many types of human-animal interaction. These interactions are the product of a very specific "environment" in which horses are not always seen as subjects but as opposed are seen as products or machines or units of value. The horse's function seems to be an important variable. Also depends upon what people want to achieve with horses. Find a friend? Go out and have fun? Compete at a local level or more serious competitive aspirations? Highest gain? In all cases, the way owners "view" their horses has an influence on the way they manage and handle them, as has been demonstrated for other domestic animals. For example, the social constructions of a companion horse or a racing horse or a horse to sell are very different. Therefore, not all interactions are intra-actions and co-being.

That is why researchers are taking an increasing interest in the bonds that form between humans and horses. Main topics are: equine sociality and culture; human-horse bonding; perceptions and representations of horses; horses uses and value across cultures; considerations of equine agency; right and welfare. Within the literature on human-horse relations there are a number of explorations of the partnership between humans and horses in terms of emotion and mobility. [21-25] 


\section{The "First" Horse: Materials and Methods}

This study focused on ideas on horses as a part of the new, emerging field of horse studies in humanities and social sciences. In this research the horses are seen as individuals having their own agency [26]. I beginning from the premise that animals are types of persons or selves that engage in joint action and symbolic interactions with humans [27], and that horses are "minded social actors" who hold perspectives and generate interactions that are worthy of serious ethnographic exploration [28].

As clarifying Hurn [29] there has been some discussion among anthropologists over how the nonhuman other should feature in ethnographic encounter and text, and the general consensus has been that anthropologists need not concern themselves with what other animals are "really like", but rather should focus on what our human informants think about them [30].

This research aims to shed light on the relationship between the human and the horse, but specifically on the relationship between an owner (first time horse owner) and his/her horse. In this context the purchase of a first horse is critical and of strategic importance in which needs to be explored.

The areas to be investigated as follows:

What is the history between horse and owner (rider)? How the owner consider his/her horse? Does the owner (rider) know their horse? What are the skills of the owner (rider) in order to understand and what signs the owner (rider) look for in order to determine the horse attitude? Which are the owners abilities to read and to respond to the message communicated by the horse? Riding is a defining feature of themselves? For our owner/rider-subjects, horse is a co-agent in creation of culture and identity? Which words, experiences, feelings informants use for portray the relation with their first horse?

Our relationship with horses are shaped by what they mean to us and what their value is to us, horses will mean something very different to different people. Research into human-horse relationships is relatively new, the existing literature supports the idea that riders, as partners to the horse and vice versa, are relational categories arising from engagements in a range of intra-acting practices that form both riders and their horses [31,32]. This research aims to offer a contribution as it proposes a framework for understanding how the human-horse interaction unfolds as a relational act and as a transformative process of mutual wellbeing. To-date, no studies on this topic have been undertaken in Italy.

This article constitutes an analysis of narrative data collected in twenty-five open-ended interviews with horse people (all owners/riders) about the experience with their first horse.

Riders participate in different equestrian activities and sports - dressage, endurance, show-jumping, driving - in two specific provinces of Italy, Umbria and Lombardia. Their ages ranged from 20 to 64 . The majority of informants were females $(n=17)$ in comparison to males $(n=8)$.

Their riding experience also ranged from 6 months through to 54 years. Interviewees were recruited at a variety of venues: riding schools, equestrian clubs.

In order to gain entry into riding schools and clubs, I initiated contact with the owners/riders through a horse vet works in various provinces of Italy; I have also recruited participants among my common-interest friendship groups. I'm also an owner/rider, affording me an insider knowledge and familiarity with the field [33].

Participants appeared to be quite comfortable while sharing information about horse in general, sports, technical competence, but talking about the relationship with his/her horse was more emotional. All participants declared that it was the first time to manifest this aspect. All interviews were conducted in Italian, audio-recorded, and later transcribed.

\section{Results}

\subsection{The Right Horse}

The purchase of a first horse is critical and of strategic importance in which needs to be explored. Choosing the right horse is an important start for a good relationship.

"Be honest with yourself about not just what you want your partner to look like, but what you need in that first relationship." (Laura)

The scientific interest on human-horse interactions is recent and data is still limited. However, we know that reactions of horses to interactions with humans are mostly the result of this interplay between their own temperament, the temperament and skills of the human and the experience acquired with humans.

It's important to match the riders experience with the temperament of the horse. It's important that inexperienced riders should not buy an inexperienced mount! This knowledge, however, seems more theoretical than implemented. Too many first-time horse owners select a horse that isn't right for them.

In my research twenty-one informants bought a horse that wasn't right for them, only four consider the match to be successful. The most frequent mismatches occur when an inexperienced horse person buys an inexperienced horse or a horse not suitable for a beginner who needs an intermediate or advanced rider. These mismatches occurred in-spite of instructors being involved in the horse-buying process. What remains evident here is that there is something wrong in this process. First, seems that horses are consider mere "objects" function for humans to real "subjects" agents in connection with the human. Second, despite the instructor/trainer involvement in the horse-buying process, there are many wrong choices.

In the words of our interviewees: 
"I often ask myself: How did she and I survive?" (Laura)

"She had a right to have a more experienced rider" (Irene)

"If I would have acquired her now, I would have handled it quite differently" (Marco)

"I bought a stallion, he was so beautiful, but afterwards I learned that a stallion is never an appropriate choice for a first time horse owner" (Giulia)

"I did not buy him, but I had no experience, maybe I was too young" (Costanza)

Riding is a collaborative practice, neither one can have a communication without the other responding. Neither one can have a good relationship if they don't take each other seriously. In those cases, conflicts and tensions can easily arise. Argent [34] holds that horses are social creatures with characteristics similar to humans in that they form collaborative alliances. Horse-human relationships evolve in complex mental and material processes that co-shape and regulate collaborative practices. According to Maurstad [35], horses appeared to learn to relate to people in ways that provide them with good quality of life. Others researchers have found that horses can lead to frustration and neuroses as buckle under exactly the same kinds of stresses that affect humans: learning difficult new tasks, boring day-to-day routines, poor relationships, negative reinforcement, insufficient rewards, and troublesome bosses (trainers). [36]

Riders also bring up issues and resulting hazards as a result of an unsuccessful match:

- Horse accidents with injuries

- Personal safety

- Changing stable and instructor

- Change of ownership

- Negative human-horse interactions

- Frustration and fear

- Bad learning

\subsection{From Interaction to Relationship}

Twenty informants claimed that their first horse was the basis for the real school of relationship and communication.

Twenty-two informants during the purchasing stage had no ethological ideas about what is natural to the horse, and about what type of approaches and timing may help develop a positive bond.

Over time, riders acquired a sense that horses are partners, subjects with minds and agency of their own. Horses have their own personalities that come out the longer you live with them. Riders got to know their horses' personalities through ongoing processes of deep engagement. As shown in the quotes from the interviews all horses are different, you must deal with them on an individual basis, and different personality.

"We really need to see things from the horse's point of view, not our own"(Leonardo)

"You must see every horse for what it is" (Valentina)

"A horse can detect a human's emotional state, intentions and needs immediately" (Paola)
Describing the relationship with his/her horse, informants provided a deeply textured account of their practices.

When riders talk about their relationship with horses, a shared sense of co-being and becoming between horse and rider emerges in their narratives.

As shown in the quotes from the interviews, riders speaks of the horse as subject and of himself as being in an inter-subjective relationship with the horse.

"Sometimes I think that he was good and patient to wait me to learn to stay with him" (Laura)

"I think they have learned more about humans than we know about ourselves" (Claudio)

"Start all bad, then through a mutual commitment we managed to create a relationship that today is good" (Lucio)

"With hard work and perseverance, then we won" (Irene)

Brandt [37] says that horse and human are co-creating a "third language". Riders says that learning to communicate takes time. Communications take place in all horse human related activities, not only in riding. Communication is more than body kinetics and goes beyond verbal language. It is also about sensations and emotions and affect. Horses are sensitive to the attentional states of humans and to cues given by humans. The positive, neutral, or negative valence of the relationship influences horses' behavior.

"We do not share a common language with nonhuman animals, but I'm sure that we can certainly communicate with them" (Laura)

"He know how to act with me" (Elisa)

"Now I know that horses have sensitive bodies and it's important to learn how to signal correct" (Irene)

"Horses are capable of emotions and feelings" (Alessandra)

For nineteen informants owning their own horse has modified the belief in the importance of having a horse in their lives.

For all, their lives would have been different without horses. The relationship is considered as involving an emotional bond. For many the horse has brought about a positive change, allowed them to discover their potential and ability, for some even "salvation".

"It 'been my rock", "My life jacket" (Marco)

"My care at a time of trouble and depression" (Alessandra)

"For me the relationship with the horse is completeness" (Barbara)

Horse had a positive impact on emotional and physical nurturance:

"unconditionally loving, understands me, reduces my stress...she is my medicine" (Leonardo, Elisa, Alessandra)

What horses can teach you is constructive for your inner relationship and with your relationship with others. Attitudes toward nonhuman animals may affect attitudes toward humans. The relationship with your own horse changes yourself, life choices, the relationships with humans and 
non-human animals. Riders learn more about being human, through a horse's eyes.

\section{"Change your view on the world" (Lucio) \\ "It gave me a chance to really evaluate who I am" (Irene) \\ "Horses test you and teach you patience" (Claudio)}

Twenty informants declared the importance of having a partner who understands this relationship, twenty-three riders claim not to be able to think about their life without horses. For all emotions, embodiment, and a sharing of the everyday life with the horse are considered central to the human-horse relationship.

\section{Discussion}

Too many first-time horse owners select a horse that isn't right for them. These mismatches occurred in-spite of trainer and/or instructors being involved in the horse buying process. What has emerged is the underestimation of the problems and hazards of unsuccessful match for all, riders and horses. Often with the first horse (but not only with the first!) patience is required, comprehension, time, so that first time horse owners develop awareness and attention to behavioral cues given by particular horse both its nature and its socio-cultural experiences. All these elements emerge as important factors that can influence the positivity or negativity of the relationship. Anthropomorphism - to ascribe a human motivation to an animal's action or response - has no place in trying to ascertain just what is motivating a horse in its relationships with humans. This study has also pointed out how the relationships between human and horses are co-constructions of both parties. Like in Maurstad et al. works [38], in my research parties intra-act, and respectively are changing and attuning to each other in order to communicate well and engage in their activities in meaningful ways: riders change, the human-with-horses are different from human-without, also riders use their new skills in engaging with other humans. "Horse-human practices are intra-actions with effects." [39]Both the horse and the human become attuned to each other's physical and mental ways, thus developing the state of co-being.

Over time, riders acquired a sense that horses are partners, subjects with minds and agency of their own. Training is about figuring out the other; training therefore constitutes practices where the parties engaged become comprehensible to each other. Riding is a physical and mental work for both species. A greater consciousness of these aspects is needed for choosing the horse because it is crucial in the establishment of a positive relationship and well-being of riders and horses.

Riders and horses work in contact zone. "These are natural cultural practices where mental and bodily performances matter in the species communication." [40-42]

Horses are parts of pairs. But "bringing in" animals to ethnographic fieldwork and anthropological theory raise complicated issues: questions of loyalties and advocacy and practical issues concerning the appropriate methodological and theoretical approaches to adopt when conducting multispecies ethnography.

How do we know what we know when the subject matter is the human-animal relationship? Understanding the human side of that relationship is one thing, but how can we ever understand the feelings, attitudes, and perceptions of the animals themselves? No horses were interviewed in my study. Their humans speak on their behalf. "There has been some discussion among anthropologists over how the nonhuman other should feature in ethnographic encounter and text, and the general consensus has been that anthropologists need not concern themselves with what other animals are "really like", but rather should focus on what our human informants think about them." [43]

\section{Limitations}

Within the literature on human-horse relations there are a number of excellent explorations of the partnership between humans and horses but none in Italy. In my article I present the findings of my research that targets specifically the question of the relationship between owner (first time horse owner) and his/her horse owners.

Given the newness of this inquiry, I elected to use qualitative methods to gain a more in-depth understanding of the owner (first time)-horse relationship. As with all qualitative research, the sample of this study is not representative of all owner-horse relationships and results are not generalizable. This research could be viewed as a "first generation" of literature on the perceptions and representations of horses in this country.

This research aims to offer a contribution as it proposes a framework for understanding how the human-horse interaction unfolds as a relational act and as a transformative process of mutual wellbeing. Based on the findings of my study, a greater attention to the subjectivity of the horse is needed in the horse-buying process. This article contributes to the emerging field of multispecies ethnography.

Suggestions for future research include exploring the meaning horses hold for people in various settings, human cultures and subcultures (breeders, horse dealer, caretakers, trainers, farriers, veterinarians, etc). These studies will provide an essential starting point for research on horse-human interactions and to uncover and specify what kind of relationships with horses provide benefits for both human and horses.

\section{Acknowledgements}

I would like to express my very great appreciation to Dr. Vittorio Maria Rocchelli for his valuable and constructive suggestions during the planning and development of this research work and for his valuable review and comments. 


\section{REFERENCES}

[1] M. DeMello, Animals and Society. An Introduction to Human-Animal Studies, Columbia University Press, New York, 2012, p.6.

[2] M. DeMello, Animals and Society. An Introduction to Human-Animal Studies, Columbia University Press, New York, 2012.

[3] S. Hurn, Humans and Other Animals. Cross- Cultural Perspectives on Human-Animal Interactions, Pluto Press, London, 2012.

[4] G. Marvin and S. McHugh, The Handbook of Human-Animal Studies, Routledge, 2014.

[5] T. Ingold (ed.), What is an animal?, Unwin Hyman, London, 1988.

[6] T. Ingold, Anthropology comes to life, General Anthropology, 17(1), pp.1-4, 2010.

[7] E. Kirksey and S. Helmreich, The Emergence of Multispecies Ethnography, Cultural Anthropology, 25 (4), 2010, pp. 546-576.

[8] E. Shanklin, Sustenance and symbol: anthropological studies of domesticated animals, Annual Review of Anthropology, 14, 1985, pp. 375-403, p. 380.

[9] B. Noske, Beyond boundaries: humans and animals, Black Rose, London, 1989.

[10] D. Haraway, The Companion Species Manifesto: Dogs, People and Significant Otherness, Prickly Paradigm Press, Chicago, 2003, p. 16.

[11] E. Kohn, How dogs dream: Amazonian natures and the politics of trans-species engagements, American Ethnologist, 34, 2007, pp. 3-24, p. 4.

[12] S. Hurn, Humans and Other Animals. Cross- Cultural Perspectives on Human-Animal Interactions, Pluto Press, London, 2012, p. 203.

[13] M. Midgley, Bridge-building at last, in A. Manning and J. Serpell (eds), Animals and human society: changing perspectives, Routledge, London, 1994, pp. 188-194.

[14] S. E. Kirksey and S. Helmreich, The Emergence of Multispecies Ethnography, Cultural Anthropology, 25 (4), 2010, pp. 546-576.

[15] R. Madden, Animals and the Limits of Ethnography, Anthrozoos, vol.27, issue 2, 2014, pp. 279-293.

[16] A. Maurstad, D. Davis and S. Cowles, "Co-being and intra-action in horse-human relationships: a multi-species ethnography of be(com)ing human and be(com)ing horse", Social Anthropology, 21,1, 2013, pp. 322-335.

[17] A. David, The Spell of the Sensuous: Perception and Language in More-Than-Human World. New York, Pantheon Books, 1996.

[18] P. Waldaus, Animal Studies in the Key of Animal Rights, pp. $1-21$, p. 2, online available from $\mathrm{http}$ //animaliajournal.com/2015/06/26/animal-studies-in-the -key-of-animal-rights.

[19] N. Edenburg, Perceptions and attitudes towards horses in European societies. Equine Vet. J., Suppl. 28, 1999, pp. $38-41$.

[20] D. Haraway, When Species Meet, University of Minnesota Press, Minneapolis, 2008.

[21] K. Brandt, Intelligent bodies: embodied subjectivity human-horse communication, in D. Waskul and P. Vannini (eds.), Body/embodiment. Symbolic interaction and the sociology of the body, Farnham Ashgate, 2006, pp. 141-153.

[22] D. Davis, A. Maurstad and S. Cowles, Riding up forest mountain sides, in wide open space, and with walls: developing the ecology of horse-human relationships, Humanimalia, 4(2), 2013, pp. 54-83.

[23] N. Savvides, "Loving-knowing" women and horses: symbolic connections, real life conflicts and "natural horsemanship", Humanimalia, 3(1), 2011, pp. 60-77.

[24] R. Evans and A. Franklin, Equine beats: unique rhythms (and floating harmony) of horses and riders, in T. Edenser (ed.), Geographies of rhythm: nature, place, mobilities and bodies, Farnham, Ashgate, pp. 173-185.

[25] M. Hausberger, H. Roche, S. Henry and E. K. Visser, A review of the human-horse relationship, Applied Animal Behaviour Science, 109, 2008, pp.1-24.

[26] S. E. McFarland and R. Hediger, Animals and Agency: An Interdisciplinary Exploration, Brill, Leiden, 2009.

[27] J.M. Alger and S.F. Alger, Cat culture: the social world of a cat shelter. Temple University Press, Philadelphia, 2003.

[28] A. Arluke and C. S. Sanders, Regarding Animals (Animals, Cultures and Society), Temple University Press, Philadelphia, 1996, pp.41-42.

[29] S. Hurn, Humans and Other Animals. Cross- Cultural Perspectives on Human-Animal Interactions, Pluto Press, London, 2012.

[30] R. Tapper, Animality, humanity, morality, society, in T. Ingold (ed.), What is an animal? Unwin Himan, London, 1994, pp. 47-72.

[31] K. Barad, Meeting the universe halfway. Quantum physics and the entanglement of matter and meaning, Duke University Press, Durham, 2007.

[32] A. Birke et al., "Animal performances. An exploration of intersections between feminist science studies and studies of human/animal relationships", Feminist Theory, 5, 2004, pp. 167-183.

[33] K. Brandt, A language of their own: an interactionist approach to human-horse communication, Society and Animals, 124, 2004, pp. 299-316.

[34] Argent G., Toward a privileging of the non-verbal: communication, corporal synchrony, and transcendence in humans and horses, in J.A. Smith, R.A. Mitchell (eds.), Experiencing animal minds: an anthology of animal-human encounters, Columbia University Press, New York, 2012, pp. 111-128.

[35] A. Maurstad, D. Davis and S. Cowles, "Co-being and intra-action in horse-human relationships: a multi-species 
ethnography of be(com)ing human and be(com)ing horse", Social Anthropology, 21,1, 2013, pp. 322-335.

[36] C. Fureix, P. Jego, S. Henry, L. Lansade, M. Hausberger, Towards an Ethological Animal Model of Depression? A Study on Horses, PLOS ONE, published 28 Jun 2012, online available from http://journals.plos.org/plosone/article?id=10. 1371/journal.pone.0039280.

[37] K. Brandt, A language of their own: an interactionist approach to human-horse communication, Society and Animals, 124, 2004, pp. 299-316.

[38] A. Maurstad, D. Davis and S. Cowles, "Co-being and intra-action in horse-human relationships: a multi-species ethnography of be(com)ing human and be(com)ing horse", Social Anthropology, 21,1, 2013, pp. 322-335.

[39] A. Maurstad, D. Davis and S. Cowles, "Co-being and intra-action in horse-human relationships: a multi-species ethnography of be(com)ing human and be(com)ing horse", Social Anthropology, 21,1, 2013, pp. 322-335, 332.

[40] A. Maurstad, D. Davis and S. Cowles, "Co-being and intra-action in horse-human relationships: a multi-species ethnography of be(com)ing human and be(com)ing horse", Social Anthropology, 21,1, 2013, pp. 322-335, 325.

[41] D. Haraway, The Companion Species Manifesto: Dogs, People and Significant Otherness, Prickly Paradigm Press, Chicago, 2003.

[42] R. Madden, Animals and the Limits of Ethnography, Anthrozoos, vol.27, issue 2, 2014, pp. 279-293.

[43] S. Hurn, Humans and Other Animals. Cross- Cultural Perspectives on Human-Animal Interactions, Pluto Press, London, 2012, p. 209. 